\title{
A análise institucional e a saúde coletiva
}

\author{
Institutional analysis and collective health
}

Abstract In its recent history, collective health has become institutionalized in a double dimension, the theoretical-practical and the political-ideological. Institutional analysis, on the other hand, is an approach aimed at changing institutions on the basis of the practices and discourses of their subjects. For this reason, there is clear potential for more widespread use of institutional analysis in collective health in the areas of research, interventions, and the training of professionals. Collective health itself can also be analyzed as a complex and contradictory institution, since it in turn involves countless other institutions.

Key words Collective health, Institutional analysis, Socioanalysis
Resumo $\mathrm{Na}$ sua história recente, a saúde coletiva se institucionalizou na dupla dimensão: teórico-prática e político-ideológica. Sendo a análise institucional uma abordagem que busca a transformação das instituições a partir das práticas e discursos dos seus sujeitos, pode-se dizer que há grande potencialidade para o crescimento da utilização do seu instrumental na saúde col etiva, consi derando as dimensões da pesquisa, da interven ção e da formação dos profissionais. A tudo isso acrescenta-se a análise da própria saúde coletiva como uma instituição complexa, contraditória, sendo ela mesma atravessada por inúmeras instituições.

Palavras-chave Saúde coletiva, Análise institucional, Socioanálise

1 Departamento de M edicina 


\section{Introdução}

Compreendida como uma abordagem que desenvolve um conjunto de conceitos e instrumentos para a análise e interven ção nas instituições, a análise institucional surge no Brasil, nos anos 70, a partir de al guns departamentos e grupos de pesquisa de universi dades brasileiras e de outras organizações, congregan do os mais diferentes tipos de profissionais. Embora tendo ampliado seu campo de atuação até o momento e venha sendo referenciada na área da saúde, através da divulgação de trabal hos de caráter acadêmico e de relato de intervenções, apenas recentemente $a$ análise institucional vem sendo aplicada no campo da saúde coletiva.

De início, é necessário esclarecer que a expressão análise institucional não tem um sentido único, pois na realidade, ela se constituiu a partir de um conjunto de disciplinas e movimentos que ocorreram na sociedade francesa, a partir dos anos 40 e 50. De acordo com Heliana de Barros Conde Rodrigues (1993) dentro do institucionalismo francês, devemos considerar a "análise institucional" e a "socioanálise", de tradição dialética, originadas sobretudo das obras de René Lourau e Georges Lapassade, e, de outro lado, a "esquizoanálise", inspirada na filosofia da diferença, relacionada a Félix Guattari e Gilles Deleuze. Como afirma a autora, é indispensável conhecer a gênese teóricoconceitual e histórica para a melhor compreensão desses campos. Reconheço, no entanto, a dificuldade de estabelecer, na produção brasileira, limites precisos entre esses campos, dado a "migração" de conceitos entre eles.

Para as finalidades deste texto, parte-se de uma primeira distinção entre anál ise institucional e socioanálise referida por H ess \& Savoye, (1993): L'analyse institutionnelle a pour but la compréhension d'une realité sociale, partant des pratiques et des énoncés de ses acteurs. La mé thode utilisée met en oeuvre un ensemble de concepts dont les principaux sont ceux d'institution, de transversalité, d'analyseur, d'implication, de commande et demande. I déalement, l'analyse est effectuée, collectivemen et en situation, par les acteurs eux-mêmes, avec ou sans le recours à des analystes extérieurs. $0 \mathrm{n}$ parle alors de socioanalyse.

No campo da saúde coletiva, as duas formas são possíveis, sobretudo quando se consideram duas dimensões de ordem mais geral, relacionadas à investigação de temas de interesse desta área.
A primeira dimensão consiste na análise institucional da saúde coletiva. Trata-se de considerar a saúde coletiva como instituição, o que significa problematizar a própria constituição do seu campo como um conjunto de saberes e práticas, relacionados a um contexto amplo, de ordem político-social, ideológica e técnicocientífica. Aqui teríamos a análise institucional, entendida como "análise de papel" (Lourau, 1975; M elo, 2000), ou como recurso a estudos de caráter sócio-histórico (Savoye, 1988).

A segunda dimensão seria a análise institucional na saúde coletiva e aqui é mais adequado referir à socioanálise. Trata-se de utilizar a socioanálise como um recurso para atuar/intervir no interior de instituições que compõem a área da saúde coletiva enfatizando os processos microssociais e micropolíticos, a partir de grupos de profissionais ou de clientela (Lourau, 1975 e 1993; H ess \& Savoye 1988 e 1993).

\section{A análise institucional da saúde coletiva}

A expressão saúde coletiva é uma invenção tipicamente brasileira que surgiu em fins da década de 1970, na perspectiva de constituir um paradigma que permitisse uma nova articulação entre as diferentes instituições do campo da saúde. Abrange atual mente um conjunto complexo de saberes e práticas relacionados ao campo da saúde, envolvendo desde organizações que prestam assistência à saúde da população até instituições de ensino e pesquisa e organizações da soci edade civil. Compreende práticas técnicas, científicas, culturais, ideológicas, políticas e econômicas (Carvalho, 2002).

$\mathrm{N}$ a década de 1970, sobretudo a partir de 1975, as importantes transformações que ocorreram na sociedade brasileira, marcadas pelo esgotamento das possibilidades do chamado "milagre econômico" e pela derrocada do governo militar, que sustentava tal modelo, produziram, de um lado, uma forte crise econômica, acentuando a dependência do país aos mercados externos e a desigualdade na distribuição de renda da população, e de outro, contribuíram para o processo de redemocratização que iria resultar, nos anos 80, na volta das eleições diretas e na criação dos novos partidos.

A crise econômica se refletia fortemente no setor da saúde. Diminuíram-se os recursos destinados à saúde pública e, em contrapartida, houve $o$ aumento dos gastos com a assistência médica individual, mediante os repasses de 
dinheiro público à Previdência Social para a compra de serviços ao setor privado. Por isso, processavam-se mudanças nas duas áreas, 0 que desde os anos 60, ocasionou um reordenamento da política de saúde para fazer face a essa crise político-financeira, principalmente porque o setor da assistência médica previdenciária sempre foi considerado hegemônico, por defender os interesses do capital.

Nesse contexto, profissionais das áreas da saúde pública e da medicina preventiva, que sempre tiveram significativa presença na cena política brasi leira através de algumas organizações de caráter científico e/ou sindical, passaram a defender o sistema público de saúde, no âmago da luta pelos direitos de cidadania, enfatizando o direito à saúde. Realmente, a questão da saúde sempre foi altamente politizada no Brasil, e o chamado "movimento sanitário" teve papel importante na resistência ao regime militar brasileiro ena luta pela democratização do país.

Assim, já em 1976, um grupo de médicos sanitaristas criava o Centro Brasilei ro de Estudos de Saúde/C ebes com o objetivo de ampliar e prosseguir "as discussões no sentido de reafirmar a íntima relação entre saúde e a estrutura social". A revista Saúde em Debate foi o veículo criado para divulgar tais discussões. A maior parte dos seus artigos e ensaios constituíam-se análises críticas ao sistema de saúde vigente, algumas feitas a partir de trabalhos acadêmicos. $M$ antendo o mesmo perfil, a revista continua a ser editada até o momento atual, tendo, portanto, 26 anos. Nos primeiros anos de sua publicação, seu principal lema era "saúde e democracia" (Saúde em Debate, 1976).

\section{A fundação da saúde coletiva como instituição}

Por que saúde coletiva? De acordo com Cecília Donnangelo (1983), num clássico artigo escrito, sob encomenda da Associação Brasileira de Pós-Graduação em Saúde Coletiva/Abrasco, a saúde coletiva deve ser entendida como uma delimitação aproximada do campo (da saúde) não através de defini ções formais, mas considerando como ponto de partida, que a posição ocupada pela Saúde Coletiva no contexto das práticas sanitárias brasilei ras se expressa atual mente em um conjunto de tendências de ampliação e recomposi ção de seu espaço de intervenção ou, correspondentemente, de seu campo de saber e prática.
A tendência de recomposição do campo apontada por Cecília D onnangelo é relevante, sobretudo quando se pensa na dicotomia reforçada ao longo do tempo, no Brasil, entre assistência médica individual e saúde pública, e na hegemonia da primeira em relação à segunda. Tal hegemonia se dá, não apenas no nível econômico, como também no ideológico, pois a prática médica, tendo como base de conhecimento científico as ciências naturais, acaba por assumir o caráter de uma aparente neutralidade e ahistoricidade, o que Ihe confere uma relativa cristalização de seu objeto e de sua prática.

Verifica-se, portanto, a necessidade de discutir o sentido da palavra "coletivo" como adjetivo de saúde. A partir da análise das principais transformações pelas quais passavam, na década de 1970, a prática médica e a própria saúde pública, e que dizem respeito ao aumento do consumo de serviços médicos dado o aumento do número de trabalhadores, com direito à assistência médica previdenciária, Cecília Donnangelo, no mesmo artigo, observava que essas questões penetraram na escola médica, através dos departamentos de M edicina Preventiva e/ou Social. Isto resultou numa produção acadêmica bastante diferenciada daquela da década anterior, sobretudo pela utilização mais intensa do instrumental teórico-metodológico das Ciências Sociais, principalmente o marxista. Assim são produzidos estudos epidemiológicos sobre o processo saúde-doença da população e estudos de política de saúde, nos quais se destacavam as investigações sobre as práticas e sobre o trabalho em saúde.

Esse conjunto de aspectos, tanto em relação à reorganização do atendimento à saúde, como ao redirecionamento da produção acadêmica, acabou por produzir a necessidade de se repensar os nomes pelos quais era conhecido o campo da saúde: "polícia médica", "medicina social", "saúde pública", "medicina preventiva", "medicina comunitária", "saúde comunitária", bem como certas dicotomias, já bastante instituídas, tais como "saúde X medicina", "medicina preventiva $X$ medicina curativa", "medicina individual X medicina social", "saúde pública $X$ assistência médica individual". Embora não tivessem esgotado totalmente seus significados e inclusive continuem a ser mencionadas, tais denominações e oposições supunham diversidades teóricas, históricas e ideológicas e não conseguiam abranger o campo da saúde em sua multiplicidade. 
Por tudo isso, conclui a autora, é exatamente devido aos muitos significados da palavra "coletivo", no âmbito das ciências sociais, que o termo, embora impreciso, é adequado para designar a diversidade de aspectos do campo da saúde. Isto porque essas variações reproduzem efetivamente a amplitude possível da gama de conotações assumidas pela noção de coletivo: coleti vo/conjunto de indivíduos; coletivo/interação entre elementos; coletivo como conjunto de efeitos ou conseqüências da vida social; coletivo transformado em social como campo específico e estruturado de práticas (D onnangelo, 1983).

Com tal multiplicidade de significados, e partindo da iniciativa de intelectuais das áreas de medicina preventiva e saúde pública, o termo saúde coletiva começou a ser utilizado no final da década de 1970, para nomear reuniões, eventos, cursos, departamentos, núcleos e institutos de pesquisa, e finalmente, para dar nome a uma entidade, a Associação Brasileira de PósGraduação em Saúde Coletiva/Abrasco (N unes, 1996).

A associação é fundada em 1979, com a finalidade de atuar como mecanismo de apoio e articulação entre os centros de treinamento, ensino e pesquisa em saúde coletiva para fortalecimento mútuo das entidades membros e para a ampliação do diálogo com a comunidade técnico-ci entífica. Enfatiza-se ain da que o compromisso maior da Abrasco e, portanto dos seus associados individuais e institucionais, vincula-se à formação de pessoal e produção de conhecimentos que contribuam para superar as desigualdades econômicas, sociais e sanitárias presentes na sociedade brasileira. Em consonância com o movimento também existente na América Latina, no mesmo período, a Abrasco pretende congregar todos os programas de pós-graduação em saúde coletiva do país, constituindose no órgão regional da Associação Latino Americana de Escolas de Saúde Pública-ALAESP ligada à Organização Pan-Americana da Saúde/OPS (Abrasco, 1983).

A pesar dessa consonância com o movimento latino-americano (N unes, 1994) somente no Brasil, esta recomposição do campo da saúde assumiu o nome de saúde coletiva. Daí a afirmação de que "inegavel mente, a saúde coletiva é uma invenção brasileira" (Canesqui, 1995).

Como referi acima, é essa associação, a Abrasco, que demandou a Cecília Donnangelo 0 artigo para discutir o conceito de saúde coletiva. Temos, então, nesses dois acontecimentos que se complementam: a criação da Abrasco em setembro de 1979 e a divulgação do artigo sobre o conceito de saúde coletiva em abril de 1983, a fundação da saúde coletiva como instituição. Assim, a criação da saúde coletiva e de sua aplicação para designar uma grande multiplicidade de eventos e atividades sejam acadêmicas, sejam político-ideológicas, centralizadas na Abrasco, teve, sem dúvida, um caráter instituinte inovador, tendo em vista o que já estava instituído na área da saúde no Brasil (Lourau, 1975 e 1993; H ess \& Althier, 1994).

É de se questionar em que medida as marcas desta origem incidem na forma como a saúde coletiva se apresenta na atualidade. Quais as transformações preservam os princípios desse momento fundador?

\section{A institucionalização da saúde coletiva pela Abrasco}

A Abrasco foi aos poucos se fortalecendo como o movimento-instituição, síntese desse sujeito histórico e epistêmico constituído pela Saúde Coletiva, de acordo com M aria Cecília de Souza Minayo, (2001).

A sua constante estruturação se dá agora num outro contexto bem diferente, pois ao final dos anos 80 e início dos anos 90, tanto a democracia, como a Reforma Sanitária, que institucionalizou o Sistema Ú nico de Saúde/SU S, encontravam-se bem mais consolidados. $\mathrm{Na}$ saúde coletiva como área da pós-graduação, avanços significativos podiam ser observados. É evidente que tais êxitos foram o resultado de várias "lutas intermediárias" e, sem dúvida, a Abrasco se fez presente nessas várias etapas (Belisário, 2002).

U ma vez percorrido este caminho, a saúde coletiva, através da Abrasco, hoje com 23 anos de existência, e 6.000 associados, encontra-se totalmente consolidada como evidenciam algumas de suas atuações e atividades mais significativas, colocadas a seguir.

No âmbito científico-acadêmico, os grupos de trabalho já constituídos (epidemiologia, ciências sociais, planejamento em saúde, vigilância sanitária, ciência e tecnologia em saúde, saúde indígena e educação popular em saúde, trauma e violência e promoção à saúde) vêm realizando e divulgando, de forma sistemática, debates e estudos que depois tornam-se subsídios para os congressos e para as publicações; no plano editorial, tem publicado vários livros e coletâneas, alguns em co-edição, e desde 1995 
publica Ciência \& Saúde Coletiva, revista que juntamente com a Revista de Saúde Pública, da Faculdade de Saúde Pública da U niversidade de São Paulo, e os Cadernos de Saúde Pública, da Escola N acional de Saúde Pública da Fundação O swaldo Cruz, são consideradas as três publicações de excelência na área da saúde. Além da revista, a Abrasco publica boletins para os associados.

No plano político-acadêmico, tem promovido grandes congressos, em diversas regiões do país ( 15 ao todo) alguns gerais, contemplando as diversas áreas que compõem a entidade, outros específicos das áreas de epidemiologia e ciências sociais, com público que tem variado de 250 a 5.000 pessoas. Devido ao grande número de participantes em seus congressos, a A brasco realiza a cada três anos um congresso geral, apelidado de "Abrascão" e, no intervalo, congressos específicos. Destes últimos, os de Ciências Sociais têm tido um público mais reduzido (de 250 a 600 pessoas) e os de Epidemiologia, um público bem mais amplo (de $2.000 \mathrm{a}$ 3.500); final mente os Congressos Gerais têm contado com um público bem mais numeroso: - VI eúltimo "Abrascão", realizado em agosto de 2000 em Salvado (BA) contou com 5.000 participantes (Belisário, 2002).

No plano da política científica participa do Fórum de Coordenadores de Pós-Graduação em Saúde Pública/Saúde Coletiva da Fundação Capes, uma das mais importantes instituições de pesquisa do Brasil, atual responsável pelo processo de avaliação de todos os cursos de pós-graduação do país, bem como pela atribuição de bolsas; e, finalmente, no cenário político-institucional, tem representação formal no Consel ho Nacional de Saúde, que exerce o controle social da Política Nacional de Saúde.

$N$ ão é difícil perceber os pontos de contato entre os planos dessas várias atuações, bem como as contradições que podem ocorrer entre os diferentes grupos, seja devido a diversas posições políticas, seja pelas disputas de ordem científica e acadêmica, seja por corporativismos. Isto ocorre, apesar do pluralismo existente hoje. Soraya Almeida Belisário sintetiza tais contradições numa das conclusões de sua tese sobre a Abrasco: misto de sociedade científica e de atuação política, (a Abrasco) evidencia sua natureza mista, ambígua, mesclada e diferenciada, cujos componentes políticos e de formação convivem e interagem, num movimento pendular, mas, ao mesmo tempo, potencializador (Belisário, 2002).

\section{A saúde coletiva e o futuro: novos desafios}

Estando nos dias atuais num processo de crescente reconhecimento e institucionalização, 0 mais provável é que a saúde coletiva, através da A brasco, continue sua trajetória como entidade científica e política, com as vantagens e desvantagens que esta dupla missão pode significar. E o "movimento pendular" terá sempre, como referência, os próprios movimentos que atravessam a área da saúde como um todo.

Em relação à produção de conhecimentos, a saúde col etiva - constituída nos limites do biológico e do social - ainda continua a ter pela frente a tarefa de investigar, compreender e interpretar os determinantes da produção social das doenças e da organização dos serviços de saúde tanto no plano diacrônico como sincrônico da história, conforme conclui Everardo Nunes, ao fazer uma retrospectiva histórica do conceito de saúde coletiva (N unes, 1994).

Em relação à análise do processo saúdedoença, por exemplo, a saúde coletiva tem tido como desafio a necessidade de incorporar novas abordagens teórico-metodológicas, sobretudo as que procedem da fenomenologia ( $\mathrm{M} \mathrm{i-}$ nayo, 1992) valorizando as dimensões do indivíduo e dos pequenos grupos, bem como das representações sociais. Trata-se, enfim de se aproximar das diversas maneiras pelas quais as pessoas experimentam o estar com saúde ou 0 sentir-se doente. Sem deixar de levar em conta as condições sociais mais amplas, estas perdem seu caráter determinante.

Quanto às práticas de saúde, trata-se de analisar como vem ocorrendo, atualmente, a convivência de atividades médicas de caráter individual como a clínica, que desde alguns anos foi incorporada às unidades básicas de saúde, com as atividades mais tradicionais da saúde pública. Trata-se também de perceber 0 usuário como uma pessoa portadora de vontades e de desejos, capaz de agir e reagir diante do que está sendo oferecido a ela como resposta às suas queixas e aos seus incômodos. Para tanto torna-se necessário aproximar a saúde coletiva de campos disciplinares como a filosofia e a psicanálise, tendo em vista a complexidade que as questões da saúde assumem na atualidade, conforme propõe Gastão Wagner de Sousa Campos (Campos, 2000a).

Outro desafio consiste em perceber os movimentos de aproximação entre a saúde coletiva e outras áreas do campo da saúde, tradicio- 
nalmente distantes. Cecília M inayo (2001) chama atenção para esse fato, comentando que assim como certas especialidades médicas, entre as quais a cardiologia e a pediatria vêm dando destaque em seus congressos para temas comumente tratados pela saúde coletiva, como "orientações sobre estilos de vida", ou "orientações em relação ao grave problema da violência doméstica", a Abrasco deve promover maior diálogo com estas e outros campos de especialidades, dentro da real preocupação com a promoção da saúde.

Trata-se, enfim de perceber, com um outro ol har as relações entre o coletivo e o individual. Trata-se de perceber que, na verdade, elas se constituem em configurações extremamente dinâmicas e mutáveis. São microprocessos num fluxo molecular permanente e contínuo, como diria Félix Guattari (1987), que atravessam o conjunto das atividades humanas, e dentre elas as relacionadas à saúde.

Enfim, como conclusão, pode-se inferir que as relações entre o coletivo e o individual constituem-se em analisadores históricos da maior importância para toda a constituição da saúde coletiva e a compreensão do seu campo de saberes e práticas. Analisadores, porque provocam, fazem a instituição saúde coletiva falar, mostrar suas contradições, seus limites e possibilidades (Lapassade, 1979; Lourau, 1975)

\section{A análise institucional na saúde coletiva}

Em relação à segunda dimensão, assinalada no início, observa-se, já há alguns anos, a crescente referência, na produção acadêmica da saúde coletiva, de categorias como sujeito, subjetividade e autonomia, abordadas, seja do ponto de vista teórico (M inayo, 2001), seja a partir de processos microssociais e/ou micropolíticos que ocorrem no interior das organizações de saúde, tais como: o processo de trabalho como "trabal ho vivo em ato" (M erhy, 2002); a relevância das relações entre "gestão e subjetividade" (Campos, 1997) ; a relevância dos processos pedagógicos (L'Abbate, 1998) e da educação em saúde (L'Abbate, 1997); a inter-relação entre as dimensões analítica, pedagógica e da gestão, na construção de um novo modelo de atenção para os serviços de saúde (Campos, 2000).

De forma geral, esses vários trabal hos apontam para a seguinte direção: sem transformar as práticas cotidianas dos profissionais dos ser- viços de saúde, não haverá mudanças na forma desses serviços funcionarem, no sentido de garantir 0 acesso, a qualidade e a resolutividade, no atendimento de saúde à população. Isso significa levar em conta alguns dos princípios fundamentais da proposta do Sistema Ú nico de Saúde, ainda que este sistema esteja já legal mente instituído praticamente em todo o país. E mais: sem levar em consideração essas dimensões, não será possível construir uma nova intersubjetividade entre os sujeitos envolvidos na produção da saúde (L'Abbate, 2001a).

Tais estudos, apesar das diferenças de aportes teóricos nos quais se fundamentam, abrem muitas possibilidades para processos de intervenção, na perspectiva da socioanálise. Trata-se de interven ções no interior das organizações de saúde que objetivam transformá-las em espaços menos burocratizados, não produtores/reprodutores de indivíduos passivos e submissos. Ou seja, intervenções, nas quais as perspectivas do sujeito, da subjetividade e da autonomia sejam respeitados e até promovidos, desde que tais processos estejam, eles mesmos, postos "em análise". É o que vem a seguir.

\section{A socioanálise na saúde coletiva: alguns processos de intervenção}

Apesar de acreditar nas possibilidades de utilização da socioanálise como ferramenta para realizar intervenções em organizações de saúde, conforme referido no início desta parte, é bastante escassa a bibliografia referente a trabalhos de intervenção, tanto na área da saúdee da saúde coletiva. 0 número de trabalhos nesse sentido tanto nas publicações francesas, às quais tenho tido acesso (Pratiques de Formation e Les Cahiers de l'Implication) como nas coletâneas brasileiras já referidas neste texto é bastante reduzido.

Nesse sentido, algumas experiências das quais participei e continuo participando diretamente são exemplares da possibilidade da utilização da socioanálise em processos de intervenção em organizações de saúde.

$\mathrm{N}$ a perspectiva da capacitação profissional, coordenei uma intervenção de longa duração (de 1993 a 1999), realizada a partir de uma encomenda da direção do Serviço Social do H ospital U niversitário da U nicamp, junto a 92 assistentes sociais, que trabal ham nos mais diversos setores do hospital. A análise dessa intervenção a partir do registro das seções e de en- 
trevistas semi-diretivas, realizadas com alguns dos participantes (L'Abbate, 2000, 2001, 2001/ 2002) revelou a importância da abordagem da socioanálise para que os assistentes sociais pudessem refletir sobre o seu papel profissional no interior de um hospital público, bem como perceber e atuar sobre a grupalidade que vinham construindo, no sentido de torná-la mais favorável a processos de trabal ho mais adequados, inovadores e produtivos. Atualmente, este trabal ho tem continuidade, praticamente com as mesmas caraterísticas, junto ao grupo do serviço social que trabalha na área de DST/ Aids.

Outra intervenção que também utiliza o instrumental da socioanálise, mas em articulação com o referencial grupalista (Barros, 1994) e de gestão e planejamento (Campos, 2000) está sendo feita por um grupo de seis profissionais, dentre os quais me incluo, a partir de uma demanda do atual secretário da saúde de Campinas, Gastão Wagner de Sousa Campos, como um suporte às equipes para lidar com o processo de mudança iniciado com a nova gestão (que assumiu em janeiro de 2001, com a eleição de um governo do Partido dos Trabalhadores), contribuindo para aumentar a capacidade de análise e de intervenção, fortalecendo o grau de autonomia das equipes, e com isso, mel horar o padrão de oferta de serviços e os resultados em termos de produção de saúde (M oura et al., 2002). Assim, desde março de 2001, vem sendo realizada uma "intervenção institucional" junto aos cinco Distritos de Saúde e ao H ospital M ário Gatti e a partir de março de 2002 incluindo também o Colegiado Gestor e as equipes de coordenação do programa de DST/Aids e da Visa da Secretaria M unicipal de Saúde de Campinas, abrangendo cerca de 145 profissionais dos níveis central e intermediário da Secretaria.

Devido ao fato dessas interven ções serem de longa duração, assumem, em determinados momentos, o caráter de uma atividade pedagógica, e em outros momentos se articularam a práticas de supervisão, avaliação e assessoria.

\section{O s profissionais da saúde coletiva e o processo de formação em análise institucional e socioanálise visando às atividades de investigação e de intervenção}

Para abordar esta temática, toma-se como referência al gumas atividades atualmente desen- volvidas no Departamento de M edicina Preventiva e Social/D M PS da Faculdade de Ciências M édicas da U nicamp, departamento que vem sendo, em certa medida, pioneiro no Estado de São Paulo, na utilização da análise institucional e da socioanálise no âmbito da saúde coletiva. Em outros estados, como Rio de Janeiro, M inas Gerais e Ceará já existem há mais tempo grupos que trabalham nas perspectivas da análise institucional, da socioanálise e da esquizoanálise (Kamkhagi \& Saidon 1987; Rodrigues, 1993; Baremblitt, 1997; Petit, 1997), mas com restrita aplicação aos campos da saúde e da saúde coletiva.

Isto porque, no caso do DM PS, as cinco áreas que o compõem - ciências sociais, epidemiologia, planejamento e administração, medicina comunitária, medicina do trabalho e saúde ambiental - criaram as condições para que, desde 1991, a pós-graduação se tornasse autônoma da Faculdade de Ciências M édicas, e passasse a denominar "pós-graduação em saúde coletiva". A partir de então, o curso adquiriu um caráter multiprofissional, pois, até aquele momento, só eram aceitos médicos como alunos, e passou a conter diferentes linhas de investigação, dentre as quais "análise institucional" e "práticas educacionais".

Em sua maioria, os alunos matriculados na pós ou os que freqüentam as disciplinas como alunos especiais são oriundos de diversos serviços de saúde, e também, em sua maioria, continuam trabalhando durante o curso da pósgraduação, dado a escassez de bolsas, atualmente. E é muito comum os alunos elegerem como objeto de pesquisa para a dissertação de mestrado ou para a tese de doutorado temas relacionados a sua prática nas organizações de saúde, na perspectiva de ter na pós-graduação, a oportunidade de "refletir sobre essa prática", desejo manifesto de vários alunos.

Assim, sob a orientação de professores do DM PS da área de planejamento e da área de ciências sociais têm sido produzidas dissertações e teses que se utilizam da análise institucional, articulando conceitos da socioanálise e da esquizoanálise.

$N$ ão caberia nos limites deste texto abordar esses trabalhos e, na realidade, essa produção deverá constituir-se objeto de uma investigação específica. No entanto, a leitura de al gumas dissertações e teses permite perceber que os conceitos da análise institucional e da socioanálise são colocados sem que se faça referência a sua gênese teórica e histórica e a referência 
à expressões, como por exemplo "intervenção institucional" não significa intervenção socioanalítica.

No sentido de contribuir para aprofundar o conhecimento sobre análise institucional, como professora da área de ciências sociais, comecei a ministrar, desde 2001, a disciplina Análise Institucional: Teoria e Prática. Essa tarefa concretizou-se, sobretudo, devido à realização de um pós-doutorado de setembro de 1999 a dezembro 2000 no Laboratório de Pesquisas em Análise Institucional, da Faculdade deCiências da Educação da U niversidade Paris 8-Saint Denis, França, sob a direção dos professores $\mathrm{Re}$ né Lourau e Antoine Savoye, o que me permitiu participar efetivamente das atividades do laboratório, e conhecer a bibliografia sobre análise institucional e socioanálise, praticamente inexistentes no Brasil. A disciplina vem despertando bastante interesse entre os estudantes de pós-graduação em saúde coletiva, e de outros profissionais das áreas de educação e assistência social, al guns participando na condição de alunos especiais. Dado o interesse dos estudantes, venho ministrando disciplinas e seminários complementares, que no semestre, iniciado em agosto de 2002, contou com uma turma de 20 alunos, e já cursaram a disciplina cerca de 35 alunos.

0 processo didático da disciplina tem sido o de introduzir os principais conceitos, de acordo com sua gênese teórica e histórica, articulando-os com textos que descrevem e analisam intervenções institucionais, sobretudo as coletâneas produzidas por grupos de profissionais do Rio de Janeiro, citadas acima.

0 contato com o referencial da análise institucional e da socioanálise tem levado os profissionais/estudantes a utilizá-lo, seja como elementos relevantes para a investigação dos temas de suas dissertações e teses, seja para compreender melhor os processos institucionais nos quais estão inseridos e a ter mais condições para atuar, ainda que na perspectiva de uma "análise interna" (Boumard, 1988). M uitas vezes, é com base nessa primeira aproximação que os alunos vão elaborando, ao longo do curso, o trabalho da disciplina, unindo assim experiência prática e reflexão teórica. Os estudantes têm sido instados a utilizar como instrumento empírico o "diário institucional", de acordo com Hess (1988) e inspirados na importância do diário de pesquisa, conforme Lourau (1988).
Embora não se pretenda que, ao final da disciplina, os alunos tornem-se socioanalistas, é provável que alguns se interessem em adquirir mais experiência nesse campo, e nesse caso seria necessário pensar em outras formas de "especialização". A questão da "especialização" em análise institucional e em socioanálise se dá entre nós de um modo bastante informal, e ela ocorre na conjunção da teoria e da prática, a partir da experiência de alguns grupos que se constituem em torno de trabalhos de intervenção e de seminários, de forma não muito diferente do que ocorreu com os analistas institucionais franceses (Lourau et al., 1972).

Nesse sentido, têm sido desenvolvidas e debatidas, dentre outras, análises sobre temas de interesse para o campo da saúde coletiva, a partir das inserções dos alunos nos diferentes serviços de saúde de Campinas, enfatizando os aspectos micropolíticos e da constituição de grupalidades, seja das equipes, seja dos usuários, sempre se reportando às dimensões mais amplas das transformações pelas quais passa o Sistema Ú nico de Saúde atualmente.

Destaca-se na realização desses diversos trabal hos a relevância da utilização do conceito de instituição em seus três momentos (instituído/instituinte/institucional ização), a percepção da transversalidade, a elucidação dos analisadores, e, sobretudo para os alunos que optam por analisar situações relacionadas diretamente a sua situação de trabalho, o contato com suas próprias implicações, o que lhes permite maior clareza das suas possibilidades e/ou impossibilidades de atuar e intervir, principalmente face aos processos de sobreimplicação (Lourau, 1994 e 1997; Guattari, 1987).

Enfim, as experiências, brevemente rel atadas, de investigação, intervenção e formação que se utilizam do referencial da análise institucional e da socioanálise aplicadas ao campo da saúde coletiva em Campinas demonstram uma articulação promissora entre as instâncias da academia e as do poder público, que gerencia os serviços de saúde, no sentido de contribuir para o seu constante questionamento. Os sujeitos imbuídos do desejo de transformar os processos cotidianos das instituições poderão encontrar nesse referencial meios potentes para colocar tais processos em análise constante, o que poderá fazer com que a saúde coletiva tenha mais condições de enfrentar criticamente os desafios permanentes com os quais se defronta. 


\section{Referências bibliográficas}

Abrasco 1983. Contribuição da Abrasco para análise do plano de reorientação. Assistência à saúde no âmbito da Previdência Social. Ensino da Saúde Pública, M edicina Preventiva e Social no Brasil 2:101-107.

Baremblitt G 1997. Tentatives de formation d'agents instituants: résumé de trente-cinq ans d'expériences. Pratiques de Formation (Analyses) 34:25-29.

Barros RDB 1994. Grupo: a afirmação de um simulacro. Tese de doutorado em psicologia clínica. PUC/São Paulo. São Paulo, 447pp.

Belisário AS 2002. Associativismo em saúde coletiva: um estudo da Associação Brasileira de Pós-Graduação em Saúde Coletiva/A brasco. Tese de doutorado em saúde coletiva. Departamento de M edicina Preventiva eSocial, Faculdade de Ciências M édicas, U nicamp. Campinas, 324pp.

Boumard P 1988. L'analyse interne, pp. 95-106. In R H ess $\&$ A Savoye (orgs.). Perspectives de l'analyse institutionnelle. Éditeurs Librairie des M éridiens Klincksieck, Paris.

Campos GWS 1997. Subjetividade e administração de pessoal, pp. 229-267. In EE M erhy \& RT Onocko (orgs.). A gir em saúde: um desafio para o público. Editora Hucitec-Lugar Editorial, São Paulo-Buenos Aires.

Campos GWS 2000. U m método para análise da co-gestão de coletivos. Editora H ucitec, São Paulo, 236pp.

Campos GWS 2000a. Saúde pública e saúde coletiva: campo e núcleo de saberes e práticas. Ciência \& Saúde Coletiva 5(2):219-230.

Canesqui AM 1995. As ciências sociais, a saúde e a saúde coletiva, pp. 16-35. In Canesqui AM (org.). Dilemas e desafios das ciências sociais na saúde coletiva. Editora Hucitec-Abrasco, São Paulo-Rio de Janeiro.

Carvalho SR 2002. Saúde coletiva e promoção à saúde: uma reflexão sobre os temas do sujeito e da mudança. Tese de doutorado em saúde coletiva. Departamento de M edicina Preventiva e Social, Faculdade de Ciências M édicas, U nicamp, Campinas. 178pp.

Centro Brasileiro de Estudos de Saúde/Cebes 1976. Revista Saúde em D ebate 1.

Donnangelo M CF 1983. A pesquisa na área da saúde coletiva no Brasil - a década de 70. Abrasco: Ensino da Saúde Publica, M edicina Preventiva e Social no Brasil 2:19-35.

Guattari F 1987. Revolução molecular: pulsações políticas do desejo ( $3 a$ ed.). Editora Brasiliense, São Paulo, 230pp.

H ess R 1988. Une technique de formation et d'intervention: le journal institutionnel (J.I.), pp. 119-138. In R H ess \& A Savoye (orgs.). Perspectives de L'analyse institutionnelle. Éditeurs Librairie des Méridiens Klincksieck, Paris.

Hess R \& Althier M 1994. L'analyse institutionnelle. Éditeurs, PUF, Paris, 130pp.

H ess R \& Savoye A 1993. L'analyse institutionnelle. Éditeurs PUF, Paris, 125pp.

Kamkhagi VR \& Saidon O (orgs.) 1987. Análise institucional no Brasil: favela, hospício, escola, Funabem. Editora Espaço e Tempo, Rio de Janeiro, 175pp.

L'Abbate S 1997. Comunicação e educação: uma prática em saúde, pp. 267-292. In EE M erhy \& RT Onocko (orgs.). Op. cit.
L'A bbate S 1998. Educação e sociedade: uma abordagem pedagógica para a odontologia, pp. 213-228. In C Botazzo \& SFT Freitas (orgs.). Ciências sociais e saúde bucal: questões e perspectivas. Editora Unesp-Edusc, São Paulo-Bauru.

L'A bbate S 2000. Trabalho de grupo einstituição. Relatório de Pesquisa. LRAI, Paris 8; Faculdade de Ciências M édicas, Unicamp, Campinas, 116pp.

L'Abbate S 2001. Prática educativa e socioanálise: a formação dos profissionais de saúde. XVII Conférence Mondiale de Promotion et Éducation pour la Santé, vol. 1. Paris.

L'A bbate S 2001a. 0 exercício de intersubjetividade como mediação entre grupos sociais e gestores nas práticas de saúde. Conferência proferida no II Seminário sobre Educação e Saúde no Contexto da Promoção da Saúde e II Encontro Nacional de Educação Popular e Saúde. Universidade de Brasília, Brasília.

L'A bbate S 2001/2002. L'argent, un analyseur de l'institution médico-sociale au Brésil. Les Cahiers de l'I mplication 5:57-69.

Lapassade G 1979. El analizador y el analista. Editora Ge disa, Barcelona, 246pp.

Lourau R et al. 1972. Groupes d' Analyse Institutionnelle: les analyseurs arrivent, pp. 1.025-1072. Les Temps M odernes 316-317.

Lourau R 1975. A análise institucional. Editora Vozes, Petrópolis, 294pp.

Lourau R 1988. Le journal de recherche. Éditeurs Librairie des M éridiens Klincksieck, Paris, 271pp.

Lourau R 1993. René Lourau na UERJ. Análise institucional e prática de pesquisa. Editora da UERJ, Rio de Janeiro, 118pp.

Lourau R 1994. Actes manqués de la recherche. Éditeurs PUF, Paris, 236pp.

Lourau R 1997. La clé des champs. Éditeurs Anthropos, Paris, 112pp.

M elo APJ 2000. Análise das relações do "mundo vidente" com a cegueira - a institucionalização do "corpo cego". Esboço de uma análise de papel, pp. 127-141. In HBC Rodrigues, M BS Leitão \& RDB Barros (orgs.). Grupos e instituições em análise. (2a ed.). Editora Rosa dos Tempos, Rio de Janeiro.

M erhy EE 2002. Saúde, a cartografia do trabalho vivo. Editora Hucitec, São Paulo,189pp.

M inayo M CS 1992. 0 desafio do conhecimento: pesquisa qualitativa em saúde. Editora Hucitec-Abrasco, São Paulo-Rio de Janeiro, 269pp.

M inayo M CS 2001. Estrutura e sujeito, determinismo e protagonismo histórico: uma reflexão sobre a práxis da saúde coletiva. Ciência \& Saúde Coletiva 6(1):720.

M oura AH et al. 2002. Análise do trabalho institucional realizado junto às equipes dos Distritos Sanitários e do Hospital Mário Gatti de Campinas/SP/Brasil. Trabalho apresentado no Seminário Franco-Brasileiro realizado em Paris 8, França, em setembro de 2002.

N unes ED 1994. Saúde coletiva: história de uma idéia e de um conceito. Revista Saúde e Sociedade 3(2): 5-21.

N unes ED 1996. Saúde Coletiva: revisitando a sua história e os cursos de pós-graduação. Ciência \& Saúde Coletiva 1(1):55-69. 
Petit S 1997. La constitution d'un Groupe de Recherche dans une U niversité au NE du Brésil: quelques implications. Pratiques de Formation, (Analyses) 34: 135-44.

Rodrigues H BC 1993. As subjetividades em revolta: institucionalismo francês e novas análises. Dissertação de mestrado. Instituto de M edicina Social, U niversidade Estadual do Rio de Janeiro, 948pp.

Savoye A 1988. Du passé, faisons l'analyse. Le traitement del'histoire, pp. 153-164. In R H ess \& A Savoye (orgs.). Op cit.

Artigo apresentado em 16/10/2002

Aprovado em 12/11/2002

Versão final apresentada em 25/11/2002 